\title{
Effects of oligofructose on appetite profile, glucagon-like peptide 1 and peptide YY3-36 concentrations and energy intake
}

\author{
Sanne P. M. Verhoef ${ }^{1 *}$, Diederick Meyer $^{2}$ and Klaas R. Westerterp ${ }^{1}$ \\ ${ }^{1}$ Department of Human Biology, Nutrition and Toxicology Research Institute Maastricht, Maastricht University, \\ 6200 MD Maastricht, The Netherlands \\ ${ }^{2}$ Sensus, Borchwerf 3, 4704 RG Roosendaal, The Netherlands \\ (Received 15 November 2010 - Revised 17 March 2011 - Accepted 22 March 2011 - First published online 17 June 2011)
}

\section{Abstract}

In rats, oligofructose has been shown to stimulate satiety hormone secretion, reduce energy intake and promote weight loss. The present study aimed to examine the effect of oligofructose supplementation on appetite profiles, satiety hormone concentrations and energy intake in human subjects. A total of thirty-one healthy subjects (ten men and twenty-one women) aged 28 (SEM 3) years with a BMI of $24.8(\mathrm{sem} 0.3) \mathrm{kg} / \mathrm{m}^{2}$ were included in a randomised double-blind, cross-over study. The subjects received $10 \mathrm{~g}$ oligofructose, $16 \mathrm{~g}$ oligofructose or $16 \mathrm{~g}$ placebo (maltodextrin) daily for $13 \mathrm{~d}$, with a 2-week washout period between treatments. Appetite profile, active glucagon-like peptide 1 (GLP-1) and peptide YY3-36 (PYY) concentrations and energy intake were assessed on days 0 and 13 of the treatment period. Time $\times$ treatment interaction revealed a trend of reduction in energy intake over days $0-13$ by oligofructose $(P=0 \cdot 068)$. Energy intake was significantly reduced (11\%) over time on day 13 compared with day 0 with $16 \mathrm{~g} / \mathrm{d}$ oligofructose (2801 (SEM 301) v. 3217 (SEM 320$) \mathrm{kJ}$, $P<0 \cdot 05$ ). Moreover, energy intake was significantly lower with $16 \mathrm{~g} / \mathrm{d}$ oligofructose compared with $10 \mathrm{~g} / \mathrm{d}$ oligofructose on day 13 (2801 ( SEM 301) v. 3177 (SEm 276) kJ, P<0.05). Area under the curve (AUC) for GLP-1 on day 13 was significantly higher with $16 \mathrm{~g} / \mathrm{d}$ oligofructose compared with $10 \mathrm{~g} / \mathrm{d}$ oligofructose ( 45 ( 13 was significantly higher with $16 \mathrm{~g} / \mathrm{d}$ oligofructose compared with $10 \mathrm{~g} / \mathrm{d}$ oligofructose and placebo (409 (SEM 35 ) $v$. 222 (SEM 19 ) and 211 ( $\mathrm{SEM} 20) \mathrm{pg} / \mathrm{ml} \times \mathrm{h}, P<0 \cdot 01$ ). In conclusion, $16 \mathrm{~g} / \mathrm{d}$ and not $10 \mathrm{~g} / \mathrm{d}$ oligofructose may be an effective dose to reduce energy intake, possibly supported by higher GLP-1 and PYY concentrations.

\section{Key words: Energy intake: Visual analogue scales: Inulin-type fructans}

The prevalence of obesity has increased worldwide to epidemic proportions. Weight gain occurs when energy intake exceeds energy expenditure for a prolonged period of time. Therefore, novel foods that promote satiety and thereby reduce energy intake may be promising tools in weight management. A potential candidate ingredient for such foods is oligofructose, a fructan obtained as a partial enzymatic hydrolysate from chicory root inulin. It is fermented in the colon, and it is especially known for its prebiotic effects and associated physiological effects $^{(1-3)}$

The hypothesis that oligofructose might have beneficial effects on energy intake is based upon rat studies ${ }^{(4,5)}$. In rats, energy intake was decreased over time in the animals fed with oligofructose compared with the animals fed with a control diet. This resulted in a decrease in epididymal fat mass and visceral adipose tissue at the end of the treatment ${ }^{(6,7)}$. In addition, glucagon-like peptide 1 (GLP-1) amide and proglucagon mRNA concentrations were found to be higher in the oligofructose-fed rats ${ }^{(6,7)}$. GLP-1 is released from enteroendocrine L-cells in response to nutrient ingestion. Fermentation of oligofructose into SCFA in the gut has been shown to promote enteroendocrine L-cell differentiation in the proximal colon by up-regulation of the differentiation factors (neurogenin 3 and NeuroD), thereby contributing to a higher endogenous GLP-1 production ${ }^{(8)}$. GLP-1 was found to be essential in the control of food intake by oligofructose, since the beneficial effects of oligofructose were totally prevented in the presence of a GLP-1 receptor antagonist ${ }^{(9)}$. In addition, GLP-1 receptor knockout mice (GLP-1R ${ }^{-1-}$ ) were completely insensitive to the actions of oligofructose ${ }^{(9)}$.

Although animal studies suggest that oligofructose may be a promising tool in the nutritional approach in controlling obesity, only a few studies have investigated the effect of oligofructose in human subjects. For instance, plasma GLP-1 concentrations significantly increased after oligofructose feeding of $20 \mathrm{~g} / \mathrm{d}$ for $7 \mathrm{~d}$ in patients with gastro-oesophageal

Abbreviations: AUC, area under the curve; GLP-1, glucagon-like peptide 1; PYY, peptide YY3-36; VAS, visual analogue scale.

*Corresponding author: S. P. M. Verhoef, fax +31 43 3670976, email s.verhoef@maastrichtuniversity.nl 
reflux disease ${ }^{(10)}$. It also has been demonstrated that inulintype fructans, added in food as fat replacement, were able to lower energy intake ${ }^{(11)}$. In a pilot study by Cani et al. ${ }^{(12)}$, a 2-week treatment with $16 \mathrm{~g} / \mathrm{d}$ oligofructose has been shown to promote satiety following breakfast and dinner, and to reduce hunger and prospective food consumption following dinner. Total energy intake per d was 5\% lower during the oligofructose treatment than during the control treatment ${ }^{(12)}$. These investigators ${ }^{(13)}$ also showed that a different type of inulin consumption of $16 \mathrm{~g} / \mathrm{d}$ led to increased plasma levels of GLP-1 and peptide YY3-36 (PYY). Recently, a 12-week treatment with $21 \mathrm{~g} / \mathrm{d}$ oligofructose has been shown to increase the area under the curve (AUC) for the anorexigenic hormone PYY and to decrease the AUC for the orexigenic hormone ghrelin $^{(14)}$. Self-reported energy intake was significantly lower in the oligofructose group, and there was a reduction in body weight of about $1 \mathrm{~kg}$ over 12 weeks $^{(14)}$.

However, information on the minimal dosage of oligofructose necessary for establishing beneficial effects is still lacking. Therefore, we performed a placebo-controlled cross-over study to examine the effect of 10 and $16 \mathrm{~g} / \mathrm{d}$ oligofructose for $13 \mathrm{~d}$ on the appetite profile, GLP-1 and PYY concentrations and energy intake in normal-weight and overweight men and women.

\section{Subjects and methods}

\section{Subjects}

A total of thirty-one healthy subjects (ten men and twenty-one women) aged $20-60$ years with a BMI of $23-28 \mathrm{~kg} / \mathrm{m}^{2}$ were recruited by advertisements in local newspapers and on notice boards at the university. The subjects underwent a screening, and all were in good health, non-smokers, not using medication (except oral contraception) and moderate alcohol users. None of the subjects had a food allergy, gained or lost more than $5 \mathrm{~kg}$ in 3 months before the study, or were cognitive dietary restrained $(\mathrm{F} 1>9)$ as assessed by a validated Dutch translation of the Three-Factor Eating Questionnaire ${ }^{(15)}$. The present study was conducted according to the guidelines laid down in the Declaration of Helsinki, and all procedures involving human subjects were approved by the Central Committee on Human Research and by the Medical Ethics Committee of the University of Maastricht (Maastricht, The Netherlands). Written informed consent was obtained from all subjects.

\section{Study design}

The study had a randomised, placebo-controlled cross-over design. It consisted of three $13 \mathrm{~d}$ supplementation periods, wherein oligofructose (Fructalose ${ }^{\circledR}$ L92, 10 or $16 \mathrm{~g}$; Sensus, Roosendaal, The Netherlands) or placebo (maltodextrin, $16 \mathrm{~g}$ ) supplements were consumed daily, separated by a 2-week washout period. Maltodextrin was selected as a placebo following previous studies on the effect of oligofructose ${ }^{(12,14)}$. Furthermore, maltodextrin has a similar taste and appearance as oligofructose. The supplements were provided in one-shot fruit drinks of $100 \mathrm{ml}$. Daily supplements were divided into two equal portions of either 5 or $8 \mathrm{~g}$, each to be consumed at home during breakfast and lunch. To determine compliance, the subjects kept the empty bottles and handed them in on later visits to the university. Potential adverse effects including flatulence, bloated feeling, abdominal rumbling and abdominal pain were monitored daily using a diary. The subjects were asked not to gain or lose weight consciously and to avoid pre- and probiotic foods as indicated on a provided list of food products. The subjects reported to the university six times at 08.00 hours after an overnight fast on days 0 and 13 of each intervention interval. They were asked to abstain from strenuous physical activity and alcohol, and not to eat or drink from 22.00 hours the night before each test day. Energy intake and appetite profile ratings were determined on days 0 and 13. GLP-1 and PYY concentrations were determined on day 13 .

\section{Study protocol}

On each test day, the subject's body weight was measured with minimal clothing in the fasting state. The subjects received a standardised breakfast at 08.30 hours consisting of $20 \%$ of the subject's individual daily energy requirements. Subject-specific daily energy requirements were derived from BMR, which was calculated from the equation of Harris-Benedict $^{(16)}$. BMR was multiplied by an activity index of 1.5 , as indicated for a sedentary day ${ }^{(17)}$. Breakfast consisted of brown bread with cheese and marmalade, and fruit yogurt (21, 62 and 17 En\% from protein, carbohydrate and fat, respectively). At 12.30 hours, the subjects received a standardised lunch, which provided $40 \%$ of the subject's individual daily energy requirements. The lunch consisted of brown bread with egg and tuna sandwich salad, tomato soup and grape juice (18, 55 and 27 En \% from protein, carbohydrate and fat, respectively). Food and energy intake were assessed on days 0 and 13 via an ad libitum dinner at 17.00 hours, which consisted of a homogeneous hot pasta meal. The dinner was weighed before and after eating. The subjects were instructed to eat till they were comfortably full. The lasagna (1350g) provided $5 \mathrm{~kJ} / \mathrm{g}$ (31, 45 and $24 \mathrm{En} \%$ from protein, carbohydrate and fat, respectively). Appetite profile ratings were measured sixteen times with regular intervals between 08.30 and 20.00 hours on days 0 and 13 . On day 13, nine blood samples were collected at 08.20, 09.00, 09.30, $10.30,12.20,13.00,13.30,14.30$ and 15.30 hours, respectively, in order to obtain GLP-1 and PYY concentrations over the day.

\section{Appetite profile}

Appetite profile ratings were evaluated using anchored $100 \mathrm{~mm}$ visual analogue scales (VAS) ${ }^{(18,19)}$. Hunger, fullness, satiety, thirst, desire to eat and prospective food consumption were measured. The scale was anchored from 'not at all' on the left to 'extremely' on the right. The participants were instructed to rate their feelings by marking the scale with a vertical line at a point that was most appropriate at that 
time. The distance from the left end of the scale to this vertical line on the scale was measured in $\mathrm{mm}$; changes from baseline were calculated by subtracting the baseline score from the score at a certain time point. On each test day, these questionnaires were completed at 08.30, 09.00, 09.30, 10.30, 11.30, $12.30,13.00,13.30,14.30,15.30,16.30,17.00,17.30,18.00$, 19.00 and 20.00 hours.

\section{Blood sampling}

On days 0 and 13, a catheter was placed into the antecubital vein for blood sampling. Blood samples were collected into tubes containing EDTA, $10 \mu \mathrm{l}$ dipeptidyl peptidase IV per $\mathrm{ml}$ blood and $50 \mu \mathrm{l}$ aprotonin per $\mathrm{ml}$ blood for measurements of PYY concentrations. For GLP-1 measurements, blood was collected into EDTA tubes containing $10 \mu \mathrm{l}$ dipeptidyl peptidase IV per ml blood. Plasma was obtained by centrifugation $\left(4^{\circ} \mathrm{C}, 1000 \mathrm{~g}, 10 \mathrm{~min}\right)$ and stored at $-80^{\circ} \mathrm{C}$ until analysed. PYY3-36 concentrations were measured with a specific and sensitive RIA (Linco Research, Inc., St Charles, MO, USA). Plasma-active GLP-1 concentrations were measured by enzyme-linked immunoradiometric assay (EGLP-35K; Linco Research, Inc.).

\section{Statistical analysis}

Data are presented as mean changes from baseline with their standard errors, unless otherwise indicated. AUC of changes from baseline over time was calculated by using the trapezoid method. A Student's $t$ test (two-tailed distribution) was carried out to determine the possible differences between the conditions. ANOVA repeated measures was carried out with a repeated covariance structure to determine possible differences in appetite ratings and energy intake between conditions and time $\times$ treatment interactions. Significance was defined as $P<0.05$. All the statistical analyses were executed with SPSS version 16.0 for Macintosh OS X (SPSS, Inc., Chicago, IL, USA).

\section{Results}

\section{Subject characteristics}

Of the thirty-one subjects, two dropped out because of personal reasons, and twenty-nine subjects (nine men and twenty women) completed the study. The baseline characteristics of these subjects are presented in Table 1. As expected, body weight and height were significantly different between men and women. Body weight did not change over time, and there were no significant differences in body weight between the conditions. Moreover, no sex differences were present with respect to changes in measured variables, so the whole group was analysed together.

\section{Appetite profile}

On day 0, the AUC for appetite profile ratings was not significantly different between the three conditions.
Table 1. Subject characteristics

(Mean values with their standard errors)

\begin{tabular}{|c|c|c|c|c|c|c|}
\hline & \multicolumn{2}{|c|}{ Total $(n$ 29) } & \multicolumn{2}{|c|}{ Men $(n 9)$} & \multicolumn{2}{|c|}{ Women (n 20) } \\
\hline & Mean & SEM & Mean & SEM & Mean & SEM \\
\hline Age (years) & 28 & 3 & 32 & 6 & 26 & 3 \\
\hline Height $(m)$ & 1.73 & 0.02 & $1 \cdot 80$ & 0.03 & $1.70^{*}$ & 0.02 \\
\hline Body weight $(\mathrm{kg})$ & 74.7 & $2 \cdot 0$ & 83.1 & 3.8 & $70 \cdot 9^{\star}$ & $1 \cdot 8$ \\
\hline BMI $\left(\mathrm{kg} / \mathrm{m}^{2}\right)$ & $24 \cdot 8$ & 0.3 & $25 \cdot 5$ & 0.6 & 24.5 & 0.4 \\
\hline Dietary restraint $\dagger$ & $6 \cdot 0$ & $0 \cdot 6$ & 4.8 & $1 \cdot 0$ & $6 \cdot 2$ & 0.7 \\
\hline
\end{tabular}

* Mean values were significantly different from those of men $(P<0.01$, by ANOVA). † Dietary restraint, factor 1 of the Three-Factor Eating Questionnaire ${ }^{(15)}$.

No time $\times$ treatment differences were present with respect to the appetite profile ratings.

\section{Peptide YY3-36 and glucagon-like peptide 1}

Fasting PYY concentrations, but not fasting GLP-1 concentrations, were significantly lower on day 13 compared with those on day 0 in all conditions (49.9 (SEM 4.4) $v .71 \cdot 2$ (SEM 3.9) $\mathrm{pg} / \mathrm{ml}$ for placebo; 46.9 (SEM 4.6) $v$. 71.9 (SEM $3.6) \mathrm{pg} / \mathrm{ml}$ for $10 \mathrm{~g} / \mathrm{d}$ oligofructose and $53 \cdot 8$ (SEM 4.7) $v .74 \cdot 1$ (sEm $3 \cdot 9) \mathrm{pg} / \mathrm{ml}$ for $16 \mathrm{~g} / \mathrm{d}$ oligofructose; $P<0 \cdot 01$ ).

After the meals, PYY concentrations significantly increased in all conditions (Fig. 1(a) and (b), P<0.05). In the morning until lunch, $\mathrm{AUC}_{0-230 \text { min }}$ for PYY was significantly higher with $16 \mathrm{~g} / \mathrm{d}$ oligofructose than with $10 \mathrm{~g} / \mathrm{d}$ oligofructose and placebo (409 (SEM 35) v. 222 (SEM 19) and 211 (SEM 20) $\mathrm{pg} / \mathrm{ml} \times \mathrm{h}, P<0 \cdot 01)$. This gradually diminished over the day, resulting in a trend towards a larger total AUC for PYY with $16 \mathrm{~g} / \mathrm{d}$ oligofructose than with $10 \mathrm{~g} / \mathrm{d}$ oligofructose or placebo $(P=0.065)$.

After the meals, GLP-1 concentrations also increased significantly in all conditions (Fig. 1(c) and (d), $P<0 \cdot 05$ ). AUC for GLP-1 was significantly higher with $16 \mathrm{~g} / \mathrm{d}$ oligofructose compared with $10 \mathrm{~g} / \mathrm{d}$ oligofructose $(P<0.05)$. In addition, AUC for GLP-1 with $10 \mathrm{~g} / \mathrm{d}$ oligofructose was significantly lower compared with placebo $(P<0 \cdot 05)$.

\section{Compliance and side effects}

Compliance was high, as shown by the empty packages returned at the end of each treatment. Incidentally, some subjects returned a full package, indicating a missed dose. The subjects also reported this in their diary, showing that missing doses remained below 5\%. Only a small proportion of these missing doses was on the day before the measurements, and no doses were missed on the day of the measurements.

Adverse effects, such as flatulence, abdominal rumbling, bloated feeling and cramps, were significantly higher for 10 and $16 \mathrm{~g} / \mathrm{d}$ oligofructose compared with placebo on several days during the treatment, respectively $(P<0.05$, data not shown). However, none of the subjects complained about side effects, and there were no significant time $\times$ treatment interactions. Also, side effects did not influence compliance, 

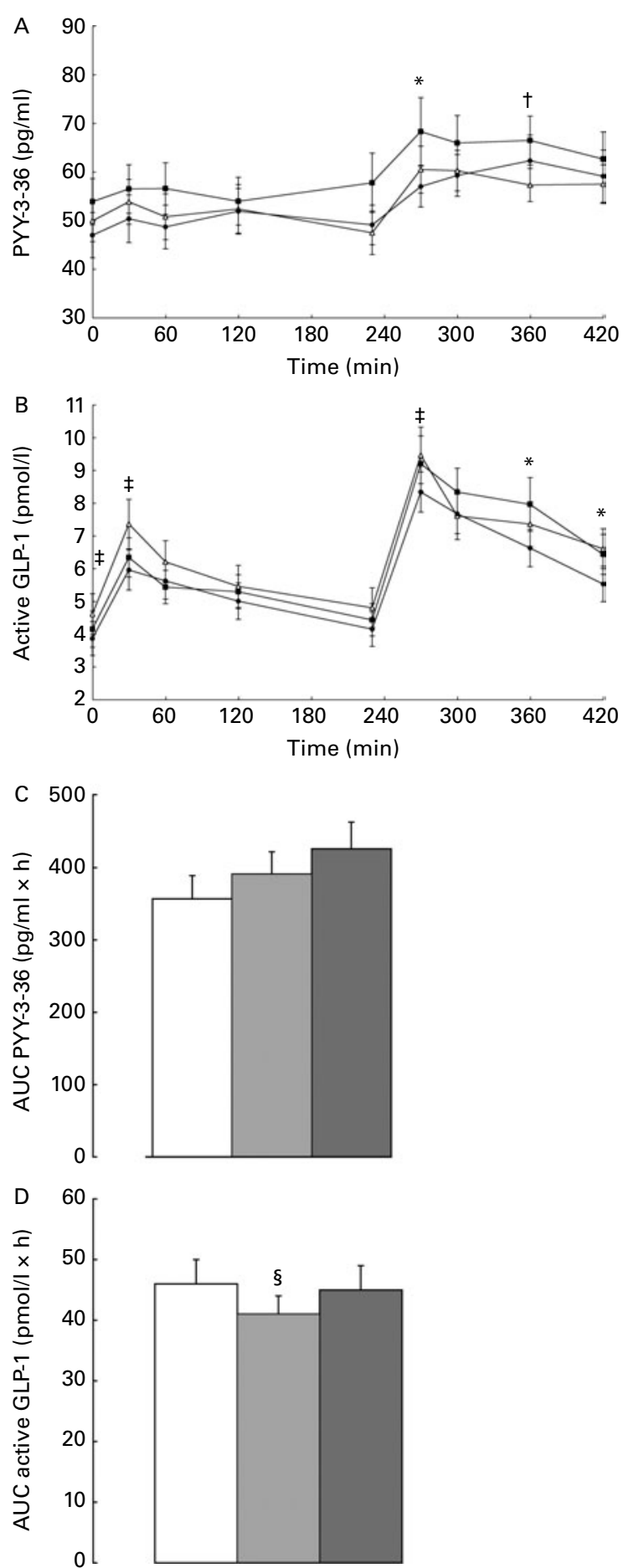

Fig. 1. Mean values for (a) plasma peptide YY3-36 (PYY; time $\times$ treatment interaction $P=0.065$ ) and (b) active glucagon-like peptide 1 (GLP-1; time $\times$ treatment interaction $P=0.041$ ) concentrations during day 13 as absolute concentrations $(\mathrm{pg} / \mathrm{ml}, \mathrm{pmol} / \mathrm{l})$ with breakfast consumed at $10 \mathrm{~min}$ and lunch at $250 \mathrm{~min}$, (c) area under the curve (AUC) for PYY3-36 and (d) AUC for active GLP-1 (pg/mml $\times$ h, pmol/l $\times$ h). $16 \mathrm{~g} / \mathrm{d}$ oligofructose $(-\mathbf{-},-\square), 10 \mathrm{~g} / \mathrm{d}$ oligofructose $(--,-\mathbb{\mathbb { }})$ ) and placebo $(-\triangle,-\square-$ ). Data were analysed by ANOVA with repeated measures. ${ }^{*}$ Mean values were significantly different between $16 \mathrm{~g} / \mathrm{d}$ oligofructose and $10 \mathrm{~g} / \mathrm{d}$ oligofructose $(P<0.05)$. † Mean values were significantly different between $16 \mathrm{~g} / \mathrm{d}$ oligofructose and placebo $(P<0.05)$. $¥$ Mean values were significantly different between $10 \mathrm{~g} / \mathrm{d}$ oligofructose and placebo $(P<0.05)$. §Mean values were significantly different between $10 \mathrm{~g} / \mathrm{d}$ oligofructose and $16 \mathrm{~g} / \mathrm{d}$ oligofructose and placebo $(P<0.05)$. since compliance was similar in the placebo treatment as with 10 and $16 \mathrm{~g} / \mathrm{d}$ oligofructose.

\section{Energy intake}

On day 0, energy intake during the ad libitum dinner was similar for all the conditions (2788 (SEM 251), 3127 (SEM 267) and 3217 (sem 321) kJ for placebo, 10 and $16 \mathrm{~g} / \mathrm{d}$ oligofructose, respectively). Subsequently, energy intake was significantly lower on day 13 after the $16 \mathrm{~g} / \mathrm{d}$ oligofructose treatment (11\%, $P<0.05$ ) compared with $10 \mathrm{~g} / \mathrm{d}$ oligofructose (2801 (SEM 301) v. 3177 (SEM 276) kJ, $P<0 \cdot 05$; Fig. 2), but not compared with placebo (2979 (SEM 276) kJ).

\section{Discussion}

In the present study, the effect of oligofructose supplementation on appetite profiles, satiety hormone concentrations and energy intake in human subjects was examined. Energy intake decreased over time with $16 \mathrm{~g}$ /d oligofructose, whereas consumption of $10 \mathrm{~g} / \mathrm{d}$ oligofructose did not change energy intake. There were no significant associations of the oligofructose-induced reduction in energy intake with appetite profile ratings.

Reduced energy intake on day 13, with $16 \mathrm{~g} / \mathrm{d}$ oligofructose was underscored by higher $\mathrm{AUC}_{0-230 \mathrm{~min}}$ of $\mathrm{PYY}$ hormone concentrations with $16 \mathrm{~g} / \mathrm{d}$ oligofructose compared with $10 \mathrm{~g} / \mathrm{d}$ oligofructose and placebo, and higher $\mathrm{AUC}_{\text {total }}$ of GLP-1 hormone concentrations with $16 \mathrm{~g} / \mathrm{d}$ oligofructose

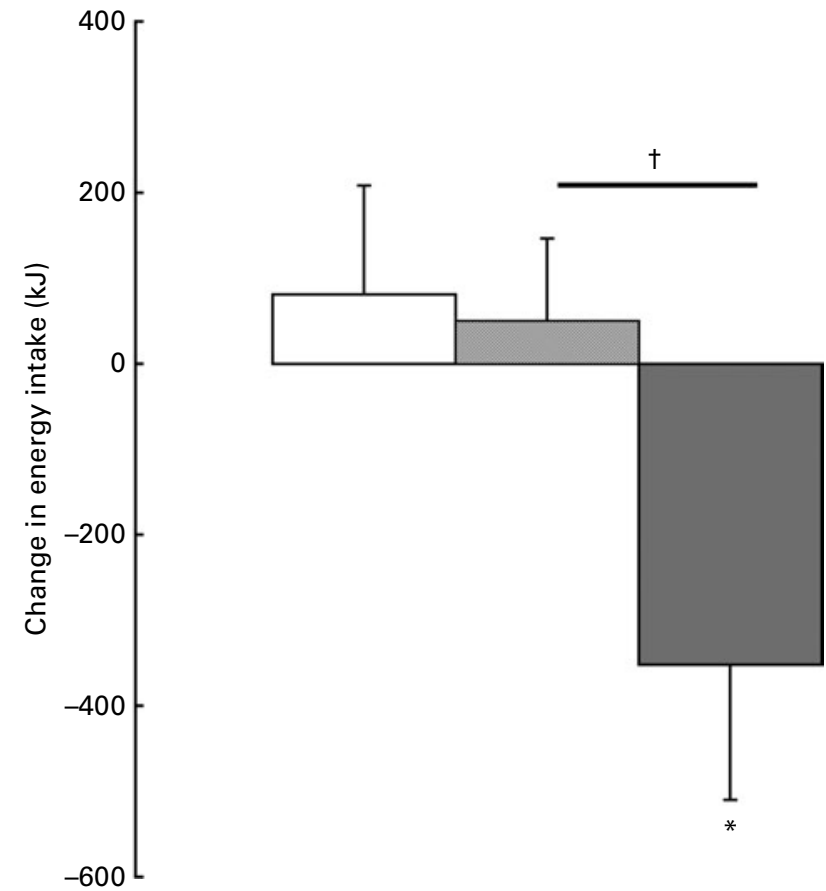

Fig. 2. Changes in energy intake (kJ) between days 0 and 13 after placebo $(\square), 10 \mathrm{~g} / \mathrm{d}$ oligofructose $(\mathbb{\mathbb { S }})$ and $16 \mathrm{~g} / \mathrm{d}$ oligofructose $(\square)$ treatment. Data were analysed by ANOVA with repeated measures. ${ }^{*}$ Mean values were significantly different from baseline $(P<0.05)$. †Mean values were significantly different between the conditions for time $\times$ treatment interaction $(P=0.068)$. 
compared with $10 \mathrm{~g} / \mathrm{d}$ oligofructose, although not significantly different from placebo. Based on rat studies ${ }^{(6,7,9)}$, it is suggested that oligofructose intake results in increased GLP-1 and PYY concentrations mediated via the SCFA, which are produced by the fermentation of oligofructose. Previous studies in human subjects showed an increased AUC for PYY with $21 \mathrm{~g} / \mathrm{d}$ oligofructose, whereas GLP-1 did not change ${ }^{(14)}$. Moreover, fasting PYY concentrations on day 13 compared with day 0 were decreased in all conditions, suggesting an effect not specifically due to oligofructose consumption. However, the subjects may have experienced a different feedback of SCFA from the colon due to the consumption of a different macronutrient and particularly fibre composition in general, resulting in an overall reduction of PYY.

The results on appetite profile ratings suggest that oligofructose does not suppress appetite. This is not consistent with previous findings ${ }^{(12)}$. On the other hand, Archer et al. ${ }^{(11)}$ could not find an effect for inulin on appetite at a lower dosage, but they did find a decrease in energy intake. However, differences in study design, such as standardised meals $v$. ad libitum and free-choice meals, and differences in population size and type of inulin used complicate comparisons between studies. In addition, measuring subjective appetite ratings with VAS can result in high variability ${ }^{(18,19)}$. Probably, oligofructose does not affect appetite feelings sufficiently to be detected with the use of VAS.

Observations on side effects as reported in the literature are not consistent. Several measurement methods are used, such as diaries, questionnaires with four-point scales ${ }^{(20)}$ or VAS questionnaires $^{(14)}$. In addition, some studies report about side effects without explaining the measurement procedures ${ }^{(12)}$ or do not report about side effects at all ${ }^{(11)}$. This makes it difficult to compare results between studies. We combined the VAS questionnaires with diaries to analyse occurrence of side effects over time. Consumption of 10 and $16 \mathrm{~g}$ oligofructose daily for 2 weeks did result in minor gastrointestinal side effects. However, no subjects complained; compliance was not affected by side effects, and we did not observe a relation of side effects with energy intake.

The observed reduction in energy intake induced by $16 \mathrm{~g} / \mathrm{d}$ oligofructose over a time interval of $13 \mathrm{~d}$ is in agreement with earlier findings ${ }^{(12,14)}$. However, differences between $16 \mathrm{~g} / \mathrm{d}$ oligofructose and placebo were not significant. Since the placebo is a polysaccharide, there might be an effect of $16 \mathrm{~g} / \mathrm{d}$ maltodextrin itself on energy intake, through which the differences between placebo and $16 \mathrm{~g} / \mathrm{d}$ oligofructose become too small in order to reach significance. Maltodextrin, in higher concentrations $(62.9 \mathrm{~g})$, has been shown to lower energy intake ${ }^{(21)}$.

Energy intake did not change with $10 \mathrm{~g} / \mathrm{d}$ oligofructose. This suggests that only $16 \mathrm{~g} / \mathrm{d}$ oligofructose is a minimal dosage to induce an effect of oligofructose on energy intake. The present results suggest that oligofructose-induced reduction in energy intake might be exerted via increased GLP-1 and PYY concentrations.

A limitation of the present study is the nature of the treatment. With such a minimal dosage, i.e. $16 \mathrm{~g} / \mathrm{d}$ compared with $21 \mathrm{~g} / \mathrm{d}$ in other studies, the study needs more sensitivity. A larger number of subjects and a longer period of time may have shown more robust results. However, we found for consumption of $16 \mathrm{~g} / \mathrm{d}$ oligofructose a trend for a time $\times$ treatment effect over $13 \mathrm{~d}$, as well as lower energy intakes on the final day of treatment. The latter was supported by higher AUC concentrations of GLP-1 and for PYY in the morning. Another limitation of the present study is that we did not measure SCFA. Although measuring SCFA in vivo in human subjects is challenging, combining SCFA measurements in both faeces and blood could contribute to explaining the mechanism behind the effect of oligofructose on energy intake.

In conclusion, $16 \mathrm{~g} / \mathrm{d}$ and not $10 \mathrm{~g} / \mathrm{d}$ oligofructose may be an effective dose to reduce energy intake in normal-weight and overweight men and women, underscored by elevated GLP-1 and PYY concentrations.

\section{Acknowledgements}

D. M. designed the study. S. P. M. V. collected and analysed the data and wrote the manuscript. K. R. W. contributed to the interpretation of the data and reviewed the manuscript. The study was executed under the supervision of K. R. W. All authors read and approved the final manuscript. The study was financially supported by Sensus. None of the authors had any conflict of interest.

\section{References}

1. Delzenne NM \& Kok N (2001) Effects of fructans-type prebiotics on lipid metabolism. Am J Clin Nutr $\mathbf{7 3}$ 456S-458S.

2. Meyer D \& Stasse-Wolthuis M (2009) The bifidogenic effect of inulin and oligofructose and its consequences for gut health. Eur J Clin Nutr 63, 1277-1289.

3. Roberfroid MB (2007) Inulin-type fructans: functional food ingredients. J Nutr 137, 2493S-2502S.

4. Delzenne NM, Cani PD, Daubioul C, et al. (2005) Impact of inulin and oligofructose on gastrointestinal peptides. Br J Nutr 93, Suppl. 1, S157-S161.

5. Delzenne NM, Cani PD \& Neyrinck AM (2007) Modulation of glucagon-like peptide 1 and energy metabolism by inulin and oligofructose: experimental data. J Nutr 137, 2547S-2551S.

6. Cani PD, Dewever C \& Delzenne NM (2004) Inulin-type fructans modulate gastrointestinal peptides involved in appetite regulation (glucagon-like peptide-1 and ghrelin) in rats. BrJ Nutr 92, 521-526.

7. Cani PD, Neyrinck AM, Maton N, et al. (2005) Oligofructose promotes satiety in rats fed a high-fat diet: involvement of glucagon-like peptide-1. Obes Res 13, 1000-1007.

8. Cani PD, Hoste S, Guiot Y, et al. (2007) Dietary nondigestible carbohydrates promote L-cell differentiation in the proximal colon of rats. Br J Nutr 98, 32-37.

9. Cani PD, Knauf C, Iglesias MA, et al. (2006) Improvement of glucose tolerance and hepatic insulin sensitivity by oligofructose requires a functional glucagon-like peptide 1 receptor. Diabetes 55, 1484-1490.

10. Piche T, des Varannes SB, Sacher-Huvelin S, et al. (2003) Colonic fermentation influences lower esophageal sphincter 
function in gastroesophageal reflux disease. Gastroenterology 124, 894-902.

11. Archer BJ, Johnson SK, Devereux HM, et al. (2004) Effect of fat replacement by inulin or lupin-kernel fibre on sausage patty acceptability, post-meal perceptions of satiety and food intake in men. Br J Nutr 91, 591-599.

12. Cani PD, Joly E, Horsmans Y, et al. (2006) Oligofructose promotes satiety in healthy human: a pilot study. Eur $J$ Clin Nutr 60, 567-572.

13. Cani PD, Lecourt E, Dewulf EM, et al. (2009) Gut microbiota fermentation of prebiotics increases satietogenic and incretin gut peptide production with consequences for appetite sensation and glucose response after a meal. Am J Clin Nutr 90, 1236-1243.

14. Parnell JA \& Reimer RA (2009) Weight loss during oligofructose supplementation is associated with decreased ghrelin and increased peptide $\mathrm{YY}$ in overweight and obese adults. Am J Clin Nutr 89, 1751-1759.

15. Stunkard AJ \& Messick S (1985) The three-factor eating questionnaire to measure dietary restraint, disinhibition and hunger. J Psychosom Res 29, 71-83.
16. Harris J \& Benedict F (1919) A Biometric Study of Human Basal Metabolism in Man. Washington, DC: Carnegie Institution of Washington.

17. Westerterp KR \& Kester AD (2003) Physical activity in confined conditions as an indicator of free-living physical activity. Obes Res 11, 865-868.

18. Flint A, Raben A, Blundell JE, et al. (2000) Reproducibility, power and validity of visual analogue scales in assessment of appetite sensations in single test meal studies. Int J Obes Relat Metab Disord 24, 38-48.

19. Stubbs RJ, Hughes DA, Johnstone AM, et al. (2000) The use of visual analogue scales to assess motivation to eat in human subjects: a review of their reliability and validity with an evaluation of new hand-held computerized systems for temporal tracking of appetite ratings. BrJ Nutr 84, 405-415.

20. Peters HP, Boers HM, Haddeman E, et al. (2009) No effect of added beta-glucan or of fructooligosaccharide on appetite or energy intake. Am J Clin Nutr 89, 58-63.

21. Yeomans MR, Gray RW \& Conyers TH (1998) Maltodextrin preloads reduce food intake without altering the appetiser effect. Physiol Behav 64, 501-506. 